Available online at www.iponlinejournal.com

\title{
Management of Xerostomia in edentulous patient associated with multiple local conditions a case report
}

\author{
Kalamalla A Saran Babu ${ }^{1 *}$, Ponnapalli Haripriya ${ }^{2}$, Srinivas Rao Pottem ${ }^{3}$, Hanuman Chalapathi Kumar Voleti ${ }^{4}$, \\ Pavan Kumar Tannamala ${ }^{5}$
}

${ }^{1}$ Assistant Professor, ${ }^{3}$ Professor and HOD, ${ }^{4,5}$ Professor, ${ }^{1,3-5}$ Dept. of Prosthodontics, ${ }^{2}$ Dept. of Pathology, ${ }^{1,3-5}$ Narayana Dental College and Hospital, Nellore, Andhra Pradesh, ${ }^{2}$ Wisdom Dental Private Hospital, Nellore, Andhra Pradesh, India

\begin{abstract}
Saliva is an important factor in determining the quality of retention in prosthetic management of edentulous conditions. Edentulism associated with multiple local conditions such as hypopigmentation, diabetes, Asthma, oral sub mucous fibrosis, multiple carious lesions etc results in decreased overall flow of salivary rate resulting in xerostomic condition. Due to this, lubricating capability of the saliva gets compromised resulting in loss of comfort and retention of removable dentures. To counteract this problem, numerous techniques have been proposed for incorporating reservoirs that contain salivary substitutes into dentures. This article describes the simplified prosthetic approach in constructing a properly functioning salivary reservoir denture to provide good lubrication to the tissues.
\end{abstract}

Keywords: Reservoir denture, Retention, Xerostomia, Artificial salivary substitute.

\section{Introduction}

According to glossary of prosthodontic terms, xerostomia is defined as dryness of the mouth resulted due to reduced or absence of salivary flow rate. ${ }^{1}$ Multiple local conditions like diabetes mellitus, multiple carious lesions, oral sub mucous fibrosis, oral candidiasis etc results in a conditions such as frequent dryness of the mouth, difficulty in normal oral and oro-pharyngeal functions. ${ }^{2,3}$ In edentulous patients with xerostomia, the salivary wetting mechanisms are necessary to create adhesion, cohesion, surface tension that helps in increased retention and comfort of the denture. Depending on the cause of xerostomia, variety of treatment options are available, such as, altering the dosage, timing or change in the medication, gustatory stimulation of the salivary glands by mastication of sugar free chewing gums or lozenges and artificial salivary substitutes. These artificial substitutes are available as solutions, sprays or gels and have multiple contents such as carboxymethyl cellulose, electrolytes and flavouring agent's e.g. wet mouth (ICPA Health Products Ltd), Oral tube etc. Often, combinations of treatments is required $^{7-10}$

Even though many artificial substitutes are available to increase the lubrication and moisture condition of the oral environment, the main problem is how to deliver these substitutes continuously in case of edentulous patients. To overcome this problem, many techniques have been put forward in complete denture fabrication; incorporating artificial salivary reservoir into denture is one such method.

This case report presents a case of a patient suffering from xerostomia with multiple local conditions who was successfully treated with a reservoir in maxillary denture where other treatment modalities have been failed.

\section{Case Report}

A 52-year-old male patient by name A. Sreenivasulu reported to the Department of Prosthodontics, Narayana Dental College, Nellore with a chief complaint of loosening of upper denture, frequent fracture of upper denture difficulty in mastication, dry feeling of the mouth and frequent need for sipping of water. The patient had a history of smoking about 10 cigarettes per day since 20 years. Medical history was contributory and the patient was on medication for Diabetes and Asthma. A systemic examination revealed dry eyes, reduced blink rate, dry mouth, cracking of corners of mouth, burning sensation and loss of appetite.

Extra oral examination revealed reduced 'vertical dimension of the face, hollow cheeks, unsupported lips, soft muscle tonicity, inadequate mouth opening and mild distortion of speech. General physical examination was normal. Intraoral examination revealed maxillary edentulous residual ridge, Lower FPD irt 31, 32, 33,41,42,43, pseudo membranous growth on hard palate, oral sub mucous fibrosis with blanching mucosa, dry cracked tongue, and minimal frothy saliva in the floor of the mouth (Fig. 1). Previous denture examination revealed inadequate vertical dimensions, inadequate cheek\& lip support, compromised retention \& stability.

Hence, a provisional diagnosis was made as 'unfavourable complete edentulous maxilla with multiple local conditions'. The patient was advised to use topical application of antifungal agents, multivitamin tablets and he was instructed to avoid dry foodstuffs like biscuits, spicy foods, smoking of cigarettes as tobacco increases oral dryness, and use a salivary substitute till the final dentures were ready. The patient was instructed for periodic recall for

\footnotetext{
*Corresponding Author: Kalamalla A Saran Babu, Dept. of Prosthodontics, Narayana Dental College and Hospital, Nellore, Andhra
} Pradesh, India

Email: ayappasaranbabu@gmail.com

http://doi.org/10.18231/j.aprd.2019.018 
every week and observed for the subside of candidal lesions. After the subside of lesions, fabrication of complete single maxillary denture with a palatal reservoir and metal base was planned.

\section{Procedure}

1. Primary impressions were made in irreversible hydrocolloid impression material (Zelgan; Dentsply, India). A special tray was fabricated and single step border moulding was completed with putty and final impression was made with light body impression material (Aquasil LV, Dentsply, India). Master cast was poured with die stone.

2. After duplication of master cast, refractory cast was poured with metavest (Delta) phosphate bonded investment material. Designing of wax pattern for cast metal base; investing; casting; finishing \& polishing; was completed. Intraoral fit of cast metal base was checked and at the same appointment bite registration was completed (Fig. 2 \& Fig. 3).

3. Teeth arrangement was completed in the articulator and try in was checked. At try in, fabrication for reservoir space was planned. Putty was adapted in the centre of the palate to determine the space for reservoir approximately without interfering with phonetics (Fig. 4).

4. Flasking was completed along with the adapted putty. After de-waxing, lost salt technique was employed in the fabrication of the reservoir space (Fig. 5). Palatal cast metal base was neatly adapted on the master cast and processing of the dentures was done in heat polymerising acrylic resin (DPI-Heat cure: Dental Products of India Ltd, Mumbai, India).

5. After Polymerisation, the denture was retrieved, finished and polished. Two holes of $1 \mathrm{~mm}$ diameter were placed in the anterior maxilla of maxillary denture and salt was completely evacuated out with hot water. Later artificial salivary substitute (Fig. 6: Wet Mouth; ICPA Health Products, Mumbai, India) is injected in to the reservoir space.

6. The patient was instructed about filling of the reservoir, cleaning of denture and proper home care (Fig. 7). The dentures were delivered and patient was trained to suck the artificial saliva from the reservoir in the denture. The patient was recalled after 72 hours for any adjustments and was scheduled for regular follow up.

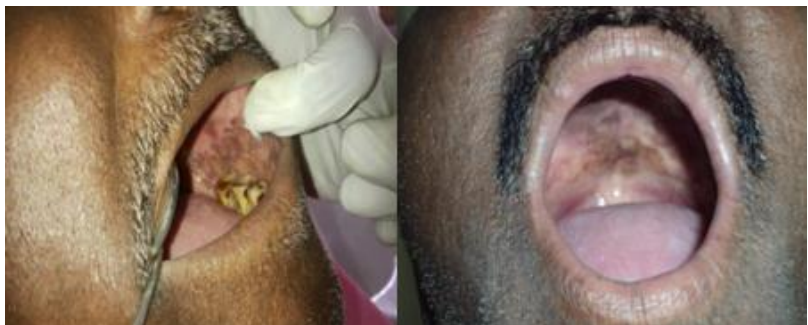

Fig. 1: Multiple local conditions (oral sub mucous fibrosis with blanching mucosa, Pseudomembranous growth on hard palate, Fissured tongue)

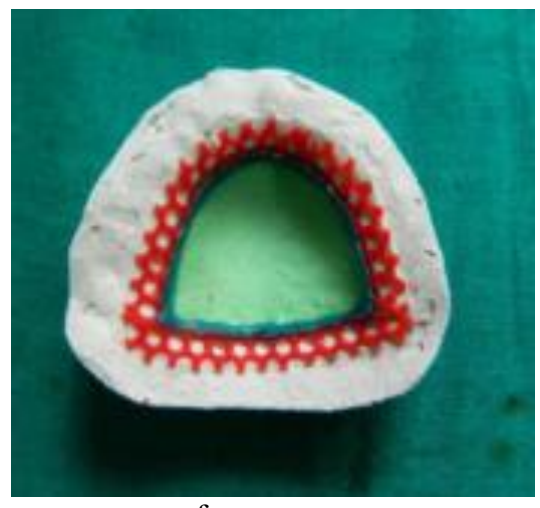

Fig. 2: Waxpattern on refractory cast.

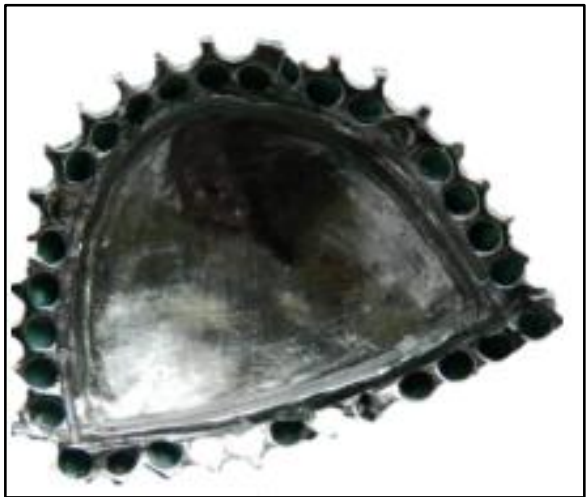

Fig. 3: Cast metal base

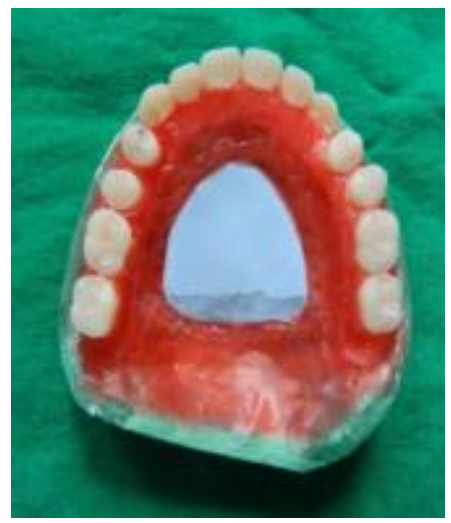

Fig. 4: Reservoir space created with putty

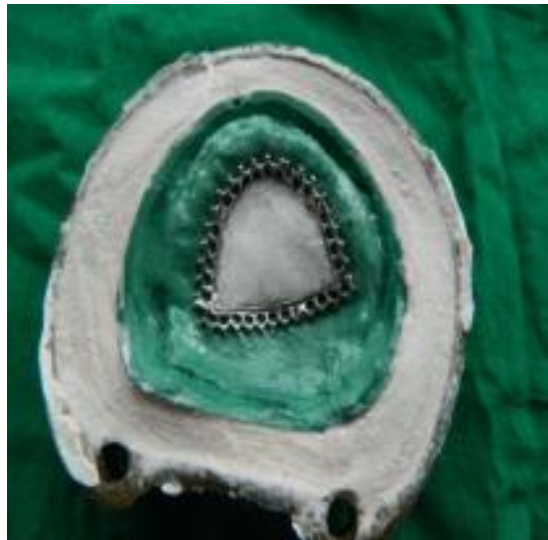

Fig. 5: Reservoir space filled with nacl 


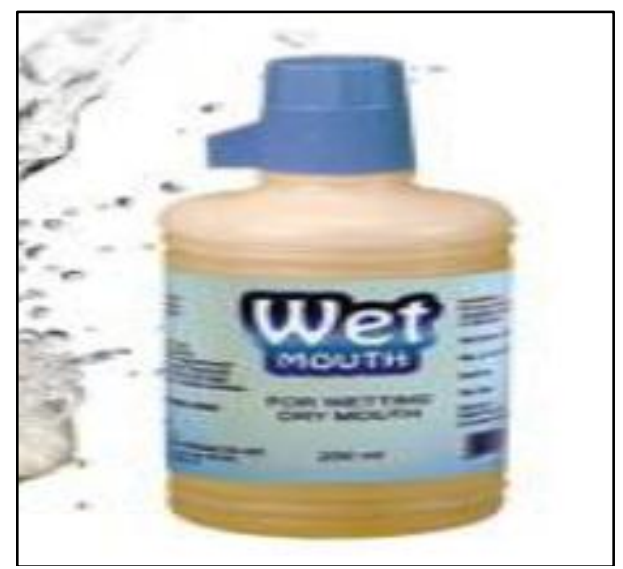

Fig. 6: Artificial substitute

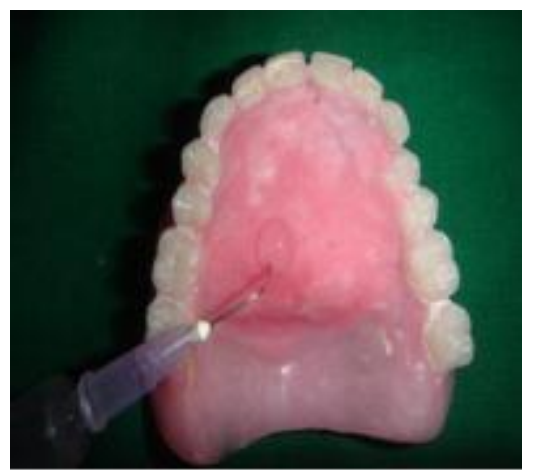

Fig. 7: Incorporation of salivary Substitute in reservoir space.

\section{Discussion}

This case report presents fabrication of a maxillary salivary reservoir denture for a patient suffering from xerostomia due to multiple local conditions where the conventional treatment modalities for fabrication of complete denture have been failed. This reservoir form of maxillary denture offers clinicians an alternative method for treating edentulous patients suffering from xerostomia.

Xerostomia, though only a symptom of a disease process or treatment regimen, can be a serious complication for a patient. A decrease in quantity or quality of saliva helps create an unhealthy oral environment. It can also cause or exacerbate a painful oral condition. Whatever may be the reason for the cause of xerostomia, dentures invariably become loose and cause discomfort for complete denture wearers.

Many treatment options for increasing salivary flow rate are available such as reducing the drug dosage, sugar free gums, artificial salivary substitutes etc. The use of sialagogues and saliva substitutes is an important step in this direction. However, it falls short when viewed from the overall concept of patient rehabilitation. The main problem is how to deliver this substitute constantly into xerostomia edentulous patient's mouth without affecting normal functions like phonetics, chewing efficiency etc. Previous studies suggest that a palatal reservoir technique may have a wide range of application ${ }^{11-14}$. Saliva substitute has been used effectively to help dialysis patients in control of water intake. ${ }^{15}$ It has also successfully aided psychiatric patients with xerostomia caused by drug regimens ${ }^{16}$. In many instances, a palatal reservoir could be incorporated into a removable partial or complete maxillary denture to act as a vehicle for delivery of saliva substitute.

Since it is a single maxillary complete edentulous condition, generally fabrication of single dentures with acrylic palatal base results in mid line fractures due to Occlusal stress on the maxillary denture and the underlying edentulous tissue from teeth and musculature accustomed to opposing natural teeth.To avoid this flexure of the denture base., cast metal base was incorporated as a palatal base to increase the strength of the denture without compromising the denture retention. ${ }^{17 .}$

At the time of delivery of the dentures, patient was given proper instructions about how to fill the reservoir space with the artificial salivary substitute and also about proper maintenance of dentures. Patient was advised to inject the salivary substitute for every $2-3 \mathrm{hrs}$ in a day.

The main advantage of this technique includes maintaining of the oral environment healthy by means of artificial salivary substitute and easy cleaning of the reservoir. Drawbacks of this technique include bulk ness of the denture, Obstruction of orifice, additional laboratory steps. But apart from this, it can be of great utility for cases of xerostomia in edentulous patients.

\section{Conclusion}

This case report provides management of a xerostomic condition in complete edentulous maxilla associated with multiple local conditions by fabricating artificial palatal salivary reservoir denture with heat cure acrylic material reinforced cast metal base. It is simple, easy to clean and provides good lubrication to oral tissues thus enhancing retention.

\section{Source of Funding}

None.

\section{Conflict of Interest}

None.

\section{References}

1. The glossary of prosthodontics terms. J Prosthet Dent 2005;94:81

2. Narhi TO, Meurman JH, Ainamo A. Xerostomia and hyposalivation: causes, consequences and treatment in the elderly. Drugs Aging 1999;15:103-116.

3. Moore PA, Guggenheimer J, Etzel KR, Weyant RJ, Orchard T. Type 1 diabetes mellitus, xerostomia, and salivary flow rates. Oral Surg Oral Med Oral Pathol Oral Radiol Endod 2001;92:281-91.

4. Edgar WM. Saliva: Its secretion, composition and functions. Br Dent J 1992;172:305-12.

5. Douglas $\mathrm{H}$. Protective and maintenance functions of saliva. Quintessence Int 1993;24:813-6.

6. Greenspan D. Xerostomia: diagnosis and management. Oncol 1996;10:7-11. 
7. Aydin K, Terzioglu H. Ulubaram K, Hasirci N.Wetting properties of saliva substitutes on acrylic resin. Int $J$ Prosthodont 1997;10:473

8. Stamoulis S. Physical factors affecting the retention of dentures. J Prosthet Dent 1962;12:857-64.

9. Niedermeier WH, Kramer R. Salivary secretion and denture retention. J Prosthet Dent 1992;67:211-6.

10. Tyson KW. Physical factors in retention of complete upper dentures. J Prosthet Dent 1967;18:90-7.

11. Mendoza AR, Tomlinson MJ. The Split denture: A new technique for artificial saliva reservoirs in complete denture. Aust Dent J 2003;48:190-4. 16.

12. Vergo TJ Jr, Kadish SP. Dentures as artificial saliva reservoirs in the irradiated edentulous cancer patient with xerostomia: a pilot study. Oral Surg Oral Med Oral Pathol 1981;51:229-33.

13. Sinclair GF, Frost PM, Walter JD. New design for an artificial saliva reservoir for the mandibular complete denture. $J$

Prosthet Dent 1996;75:276-280.
14. Toljanic JA, Zucuskie TG. Use of a palatal reservoir in denture patients with xerostomia. J Prosthet Dent 1984;52:540-44.

15. De-Now, A. I and Czaczkes, J. W: Saliva substitute as tool in decreasing overdrinking in dialysis patients. 1980;16-43.

16. Farm, L'. E.. and Shannon, L.: A treatment for dry mouth in psychiatric patients. Am J Psychiatry 1978;135:251.

17. Driscoll CF, Masri RM:Single maxillary complete denture. Dent Clin North Am 2004;48(3):567-83,

How to cite this article: Saranbabu KA, Haripriya P, Pottem SR, Voleti HCK, Tannamala PK. Management of Xerostomia in edentulous patient associated with multiple local conditions a case report. Ann Prosthodont Restor Dent 2019;5(3):76-9. 